\title{
Large Neck and Strong Ostium Inflow as the Potential Causes for Delayed Occlusion of Unruptured Sidewall Intracranial Aneurysms Treated by Flow Diverter
}

\author{
(D) T. Su, (DP. Reymond, (D). Brina, (D) P. Bouillot, (D) P. Machi, (D) B.M.A. Delattre, (D). Jin, (D) K.O. Lövblad, and (D).I. Vargas
}

\begin{abstract}
BACKGROUND AND PURPOSE: Flow diverter-induced hemodynamic change plays an important role in the mechanism of intracranial aneurysm occlusion. Our aim was to explore the relationship between aneurysm features and flow-diverter treatment of unruptured sidewall intracranial aneurysms.
\end{abstract}

MATERIALS AND METHODS: MR imaging, 4D phase-contrast, was prospectively performed before flow diverter implantation in each patient with unruptured intracranial aneurysm. Two postprocedure follow-ups were scheduled at 6 and 12 months. Responses were grouped according to whether the aneurysms were occluded or remnant. Preprocedural aneurysm geometries and ostium hemodynamics in 38 patients were compared between the 2 groups at 6 and 12 months. Receiver operating characteristic curve analyses were performed for significant geometric and hemodynamic continuous parameters.

RESULTS: After the 6-month assessment, 21 of 41 intracranial aneurysms were occluded, and 9 additional aneurysms were occluded at 12 months. Geometrically, the ostium maximum diameter was significantly larger in the remnant group at 6 and 12 months (both $P<.001)$. Hemodynamically, the proximal inflow zone was more frequently observed in the remnant group at 6 months. Several preprocedural ostium hemodynamic parameters were significantly higher in the remnant group. As a prediction for occlusion, the areas under the curve of the ostium maximum diameter (for 6 and 12 months), systolic inflow rate ratio (for 6 months), and systolic inflow area (for 12 months) reached $0.843,0.883,0.855$, and 0.860 , respectively.

CONCLUSIONS: Intracranial aneurysms with a large ostium and strong ostium inflow may need a longer time for occlusion. Preprocedural 4D flow MR imaging can well illustrate ostium hemodynamics and characterize aneurysm treatment responses.

ABBREVIATIONS: $\mathrm{FD}=$ flow diverter; $\mathrm{PC}=$ phase-contrast; $\mathrm{RA}=$ rotational angiography

ntracranial aneurysm can cause hemorrhage associated with high mortality or residual neurologic deficits. ${ }^{1}$ Compared with surgical clipping, interventions with lower complication rates and a shorter inpatient stay are preferred. With respect to intervention, the use of a flow diverter (FD) has recently been introduced for cerebral aneurysms. Previous studies showed that procedurerelated complications, including ischemia or hemorrhage, did not differ between the FD and the coil groups, but flow diversion could provide higher occlusion rates and fewer necessary re-

Received October 13, 2019; accepted after revision December 23.

From the Department of Interventional Radiology (T.S., L.J.), Beijing Friendship Hospital, Capital Medical University, Beijing, People's Republic of China; Division of Neuroradiology and Neuro-Interventional Radiology (P.R., O.B., P.M., K.O.L., M.I.V.), and Division of Radiology (B.M.A.D.), University Hospitals of Geneva, Geneva, Switzerland; and Department of Quantum Matter Physics (P.B.), University of Geneva, Geneva, Switzerland.

This work originated at University Hospitals of Geneva, 4 Rue Gabrielle-PerretGentil, Geneva 1211, Switzerland.

Supported by Swiss National Funds (SNF 32003B_160222 and SNF 320030_156813) and Beijing Li Huanying Medical Foundation (2017). treatments, especially for the sidewall type of aneurysm in the tortuous ICA. ${ }^{2,3}$

On the one hand, the hemodynamic dampening effect by flow diversion is considered to play an important role in the mechanism of aneurysm occlusion. Results from different research groups showed the reduction of inflow velocity and intra-aneurysm flow velocity after FD deployment. ${ }^{4-6}$ Hemodynamically, they were related with specific metal coverage and porosity of the $\mathrm{FD}^{7}$ On the other hand, the influence of aneurysm features on FD treatment responses remains unclear, and some treated aneurysms remain

\footnotetext{
Previously presented at: Radiological Society of North America 105th Scientific Assembly, Chicago, Illinois, December 1-6, 2019.

Please address correspondence to Maria Isabel Vargas, MD, Division of Neuroradiology, University Hospitals of Geneva, 4 Rue Gabrielle-Perret-Gentil, Geneva 1211, Switzerland; e-mail: Maria.I.Vargas@hcuge.ch

- Indicates open access to non-subscribers at www.ajnr.org

E Indicates article with supplemental on-line appendix and table.

Indicates article with supplemental on-line photo.

http://dx.doi.org/10.3174/ajnr.A6413
} 
Table 1: Inclusion and exclusion criteria for patient selection

\begin{tabular}{|c|c|}
\hline Inclusion Criteria & Exclusion Criteria \\
\hline $\begin{array}{l}\text { Image-based evidence of a sidewall intracranial aneurysm } \\
\text { interventionally treated only by using a FD in our } \\
\text { institution }\end{array}$ & $\begin{array}{l}\text { Unavailable aneurysm-related } \\
\text { 4D PC MRI data }\end{array}$ \\
\hline $\begin{array}{l}\text { No history of related subarachnoid hemorrhage or other } \\
\text { rupture clues }\end{array}$ & $\begin{array}{l}\text { Fusiform aneurysms without a } \\
\text { well-defined ostium }\end{array}$ \\
\hline No previous invasive treatment for target aneurysm & Undesirable deployment of FD \\
\hline $\begin{array}{l}\text { Preprocedural acquisition of } 4 D \text { PC MRI and 3D RA, and } \\
\text { at least CE MR imaging or DSA follow-up with } \\
\text { conclusive results at } 6 \text { or } 12 \text { months }\end{array}$ & Missing all scheduled follow-ups \\
\hline
\end{tabular}

Note:-CE indicates contrast-enhanced.

patent in clinical practice, ${ }^{8,9}$ probably due to other hemodynamic reasons. Our experience with the utilization of $4 \mathrm{D}$ phase-contrast (PC) MR imaging for intracranial aneurysms helps us to investigate this reason before the deployment of an FD. By applying numerical simulation for a virtual flow diversion, computational fluid dynamic analyses have been used to evaluate the hemodynamic reduction inside the aneurysm. ${ }^{5,10,11}$ However, because of their specific assumptions, little predictive information on aneurysm outcome after flow diversion was provided.

In this study, we used 4D PC MRI, a powerful in vivo analytic tool that has already been used for the assessment of intra-aneurysmal flow modification after FD treatment ${ }^{6}$ to explore aneurysm hemodynamics and outcome. Other research groups have reported flow conditions at the aneurysm neck with an in vivo hemodynamic assessment by using a $1.5 \mathrm{~T}$ MR scanner and with an emphasis on the measurability and influential factors of neck flow. ${ }^{12-14}$ Nevertheless, to our knowledge, few reports have investigated the relationship between the ostium and FD treatment response. $^{15,16}$ We hypothesized that different FD treatment responses were related to aneurysm features, and our study focused on the aneurysm geometries and hemodynamics at the ostium. The aim of this study was to perform an in vivo investigation of the relationship between aneurysm features, particularly the geometric and hemodynamic parameters and their impact on FD treatment responses.

\section{MATERIALS AND METHODS Patients}

We conducted a prospective study of 41 patients ( 4 men, 37 women; mean \pm standard deviation (SD) age, $53.8 \pm 13.1$ years, [range, 26-81 years]) diagnosed with unruptured sidewall intracranial aneurysm and accepted for an FD procedure between November 2012 and November 2017. Two women were excluded because of preprocedural 4D PC MRI acquisition problems. One man was excluded because the follow-up examination showed a proximal displacement of the FD, which resulted in insufficient ostial coverage. Ethics approval was granted by the local ethics committee, and patient consent was obtained. Inclusion and exclusion criteria are shown in Table 1.

\section{Image Acquisition and Postprocessing}

MR imaging was performed within 72 hours before the endovascular procedure with a 3T PET/MR system (Ingenuity TF; Philips Healthcare, Best, the Netherlands) and an 8-channel head coil.
After 3D TOF imaging, 4D PC MRI acquisition slabs were positioned to cover the aneurysm bulge and its adjacent parent vessel. This sequence, triggered with the cardiac frequency, included velocity encoding in the 3 directions with the following parameters: field of view $190 \times 210 \mathrm{~mm}^{2}$, typically 32 slices (adjusted according to the aneurysm), acquisition voxel size $1 \times 1 \times 1 \mathrm{~mm}^{3}$ reconstructed with $0.82 \mathrm{~mm}^{3}$, sensitivity encoding acceleration factor 2, TR/TE $4.6 / 2.9 \mathrm{~ms}$, and acquisition time $13 \mathrm{~min}$. The number of cardiac phase acquisitions was based on the heart rate, and it typically ranged from 14 to 16 in this study. ${ }^{6}$ The 3D rotational angiography (RA) was acquired before FD stent implantation with a biplane angiographic unit (Allura FD20; Philips Healthcare). ${ }^{6}$ After raw data postprocessing (see Supplemental Materials and Methods) from the 4D PC MRI and 3D RA, ${ }^{17,18}$ velocity field information and the parent vessel flow rate were acquired for further analysis.

\section{Geometric and Hemodynamic Parameters}

Each aneurysm ostium plane was defined as the location from which the aneurysm sac bulged out of its parent vessel. Aneurysm sac size, perpendicular height, maximum height, ostium maximum diameter, and ostium area were measured on preprocedural 3D RA images. ${ }^{19}$ Aspect ratio (the ratio of aneurysm perpendicular height to the average ostium diameter) and size ratio (the ratio of the aneurysm maximum height to the parent vessel diameter) were computed on geometric parameters according to previously described formulas. ${ }^{20}$ Image management and geometric measurements were performed with OsiriX MD (version 9.5; http://www.osirix-viewer.com).

According to velocity field information, hemodynamic parameters at the aneurysm neck were evaluated on the opensource software Paraview (version 5.6.0; Kitware, Clifton Park, New York). The hemodynamic inflow zone at the aneurysm neck level was qualitatively evaluated at the systolic peak, and its location was trichotomously classified as proximal, lateral side, and distal neck by 2 independent analysts, with a final consensus (Fig 1). ${ }^{13}$

The following hemodynamic quantitative parameters related to the ostium were based on the inflow velocity components that were normal to the ostial plane. Hemodynamic parameters of maximum inflow velocity and mean inflow velocity were computed at the systolic time. Only mean inflow velocity was spatially averaged over the inflow area. The maximum inflow rate was the product of the mean inflow velocity and systolic inflow area at the ostium. The systolic inflow rate ratio was the ratio of the maximum inflow rate at the ostium to the systolic flow rate in the parent vessel. The parent vessel flow rate was computed and averaged from different cross-sectional planes of the parent artery proximal to the aneurysm during the complete cardiac cycle. 

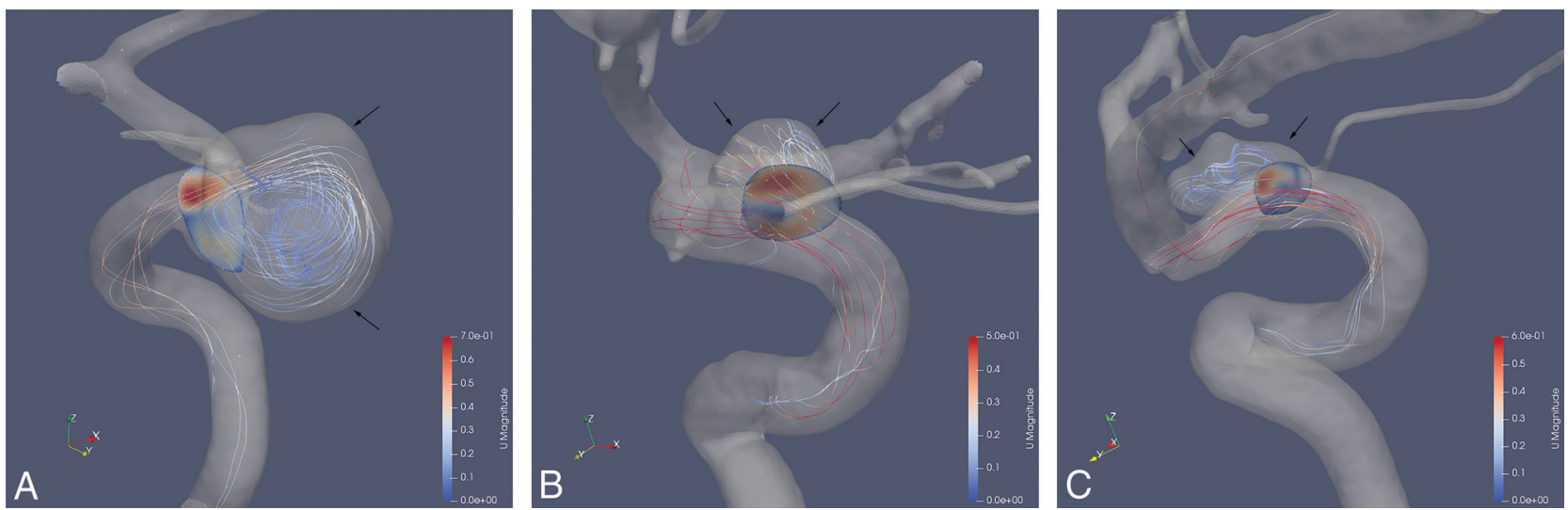

FIG 1. Different inflow zones at the aneurysm neck during systolic peak on (Paraview software). All blood flow directions are shown from the bottom to the top of the image. A, Proximal: aneurysm (black arrows) located at the medial C6 (ophthalmic/supraclinoid) segment of the right ICA and the inflow zone (red region in the aneurysm ostium) on the proximal part of the neck. $B$, Lateral side: aneurysm (black arrows) located at the dorsal C6 segment of the left ICA and inflow zone (red region in the aneurysmal ostium) on the lateral side of the neck. C, Distal: aneurysm (black arrows) located at the dorsal C6 segment of the right ICA and inflow zone (red region in the aneurysmal ostium) on the distal part of the neck.
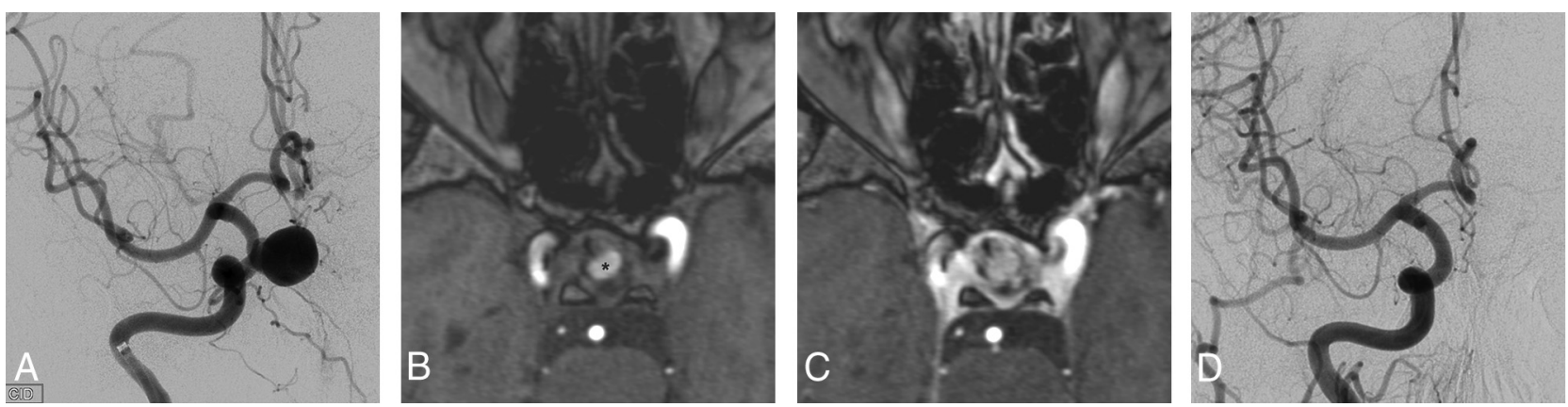

FIG 2. A 50-year-old man with an unruptured sidewall aneurysm at the medial C6 segment of the right ICA (the same case shown in Fig $1 A$ ). $A$, An initial anteroposterior angiogram of the intracranial segment of the ICA of the aneurysm. $B$, A follow-up at 6 months by using an axial 3D TOF sequence, showing partial thrombosis (*); the dark portion in the right ICA was the artifact that resulted from the FD. C, Axial 3D TOF sequence with gadolinium (acquired immediately after image $B$ ) showed enhancement inside the aneurysm compared with image $B$, and described a remnant. $D$, A follow-up anteroposterior angiogram of the intracranial segment of the ICA at 12 months did not show any residual, which represented a complete occlusion.

\section{Interventional Procedures and Follow-Up}

FD selection (see Supplemental Materials and Methods) was determined by navigability and implantation issues. No combination of coils was used. FDs were deployed by an experienced neurointerventionist, followed by a conebeam CT to confirm proper deployment. MR imaging follow-ups were completed on $3 \mathrm{~T}$ scanners with routine and appropriate technical parameters in sequences of T1WI, T2WI, 3D TOF-MRA, contrast-enhanced MRA, and contrast-enhanced T1WI. Diagnostic angiographic follow-ups performed by the same neurointerventionist focused on the target aneurysms. For the diseased side of the ICA, 2D DSA and 3D RA were acquired by following standard protocols. ${ }^{21}$

According to 6- and 12-month contrast-enhanced MR imaging or DSA follow-ups by using a simplified 2-grade scale, ${ }^{22,23}$ FD-treated aneurysms were classified as either "occlusion" or "remnant" by 2 experienced neuroradiologists blinded to each other (Fig 2). In the case of a disagreement, a third expert was asked for a decision. Additional follow-up for extra time was not suggested because other treatment options were adopted for remnant aneurysms after the 12-month follow-up. All the investigators were blinded to the acquisition parameters from the follow-up periods.

\section{Statistical Analyses}

Statistical analyses were performed by using PAWS Statistics (version 18.0; IBM, Armonk, New York). Interrater reliabilities were evaluated with the Cohen kappa coefficient $(\kappa)$ for the preprocedure inflow zone classification and image follow-up assessment. Due to analytical consideration $\chi^{2}$ analyses were performed to compare different inflow zones (proximal versus lateral side and distal neck) between the occlusion and remnant groups at the 2 follow-up time points. Preprocedural geometric and hemodynamic continuous parameters between the 2 groups were compared by using the Student $t$ test. Receiver operating characteristic curve analyses and the Youden index were performed for the most significantly different geometric and hemodynamic continuous parameters. ${ }^{24-26} P<.05$ was considered statistically significant. 
Table 2: Preprocedural geometric and hemodynamic continuous parameters for different aneurysm treatment response groups at 6 months

\begin{tabular}{lcccc}
\hline \multicolumn{1}{c}{ Parameter } & $\begin{array}{c}\text { Remnant, } \\
\text { Mean } \pm \text { SD } \\
(\boldsymbol{n}=19)\end{array}$ & $\begin{array}{c}\text { Occlusion, } \\
\text { Mean } \pm \text { SD } \\
(\boldsymbol{n}=\mathbf{2 1})\end{array}$ & $\boldsymbol{t}$ & $\boldsymbol{P}$ \\
\hline Aneurysm sac size, $\mathrm{mm}$ & $12.58 \pm 4.91$ & $7.36 \pm 3.59$ & 3.867 & $<.001$ \\
Perpendicular height, $\mathrm{mm}$ & $9.29 \pm 4.41$ & $5.61 \pm 2.88$ & 3.089 & .004 \\
Maximum height, $\mathrm{mm}$ & $10.36 \pm 4.55$ & $6.15 \pm 2.99$ & 3.418 & .002 \\
Ostium maximum diameter, mm & $6.64 \pm 2.76$ & $3.46 \pm 0.71$ & 4.873 & $<.001$ \\
Ostium area, mm ${ }^{2}$ & $41.43 \pm 26.73$ & $15.61 \pm 9.05$ & 4.007 & .001 \\
Size ratio & $2.74 \pm 1.30$ & $1.77 \pm 1.30$ & 2.353 & .02 \\
Aspect ratio & $1.49 \pm 0.62$ & $1.62 \pm 0.80$ & -0.572 & .57 \\
Maximum inflow velocity, $\mathrm{m} / \mathrm{s}$ & $0.354 \pm 0.176$ & $0.245+0.111$ & 2.336 & .03 \\
Mean inflow velocity, $\mathrm{m} / \mathrm{s}$ & $0.132 \pm 0.066$ & $0.101+0.049$ & 1.670 & .10 \\
Maximum inflow rate, $\mathrm{mL} / \mathrm{s}$ & $2.451 \pm 1.599$ & $0.817 \pm 0.579$ & 4.211 & $<.001$ \\
Systolic inflow rate ratio & $0.519 \pm 0.307$ & $0.167 \pm 0.130$ & 4.639 & $<.001$ \\
Systolic inflow area, $\mathrm{mm}{ }^{2}$ & $19.49 \pm 11.79$ & $7.47 \pm 4.40$ & 4.188 & $<.001$ \\
Parent vessel flow rate, $\mathrm{mL} / \mathrm{s}$ & $3.17 \pm 0.75$ & $3.50 \pm 0.64$ & -1.509 & .14 \\
\hline
\end{tabular}

Note:-SD indicates standard deviation.

Table 3: Preprocedural geometric and hemodynamic continuous parameters for different aneurysm treatment response groups at 12 months

\begin{tabular}{lcccc}
\hline \multicolumn{1}{c}{ Parameter } & $\begin{array}{c}\text { Remnant, } \\
\text { Mean } \pm \text { SD } \\
(\boldsymbol{n}=10)\end{array}$ & $\begin{array}{c}\text { Occlusion, } \\
\text { Mean } \pm \text { SD } \\
(\boldsymbol{n}=\mathbf{3 0})\end{array}$ & $\boldsymbol{t}$ & $\boldsymbol{P}$ \\
\hline Aneurysm sac size, $\mathrm{mm}$ & $15.00 \pm 4.78$ & $8.08 \pm 3.74$ & 4.722 & $<.001$ \\
Perpendicular height, $\mathrm{mm}$ & $11.72 \pm 4.50$ & $5.86 \pm 2.75$ & 4.942 & $<.001$ \\
Maximum height, mm & $12.52 \pm 4.76$ & $6.64 \pm 3.07$ & 4.545 & $<.001$ \\
Ostium maximum diameter, $\mathrm{mm}$ & $7.69 \pm 2.60$ & $4.12 \pm 1.70$ & 4.954 & $<.001$ \\
Ostium area, mm ${ }^{2}$ & $50.26 \pm 26.69$ & $20.82 \pm 16.48$ & 3.286 & .007 \\
Size ratio & $3.36 \pm 1.30$ & $1.85 \pm 1.19$ & 3.392 & .002 \\
Aspect ratio & $1.55 \pm 0.60$ & $1.44 \pm 0.75$ & 0.195 & .85 \\
Maximum inflow velocity, $\mathrm{m} / \mathrm{s}$ & $0.294 \pm 0.133$ & $0.302+0.160$ & -0.143 & .89 \\
Mean inflow velocity, $\mathrm{m} / \mathrm{s}$ & $0.105 \pm 0.034$ & $0.121+0.065$ & -0.722 & .48 \\
Maximum inflow rate, $\mathrm{mL} / \mathrm{s}$ & $2.382 \pm 1.306$ & $1.354 \pm 1.373$ & 2.074 & .04 \\
Systolic inflow rate ratio & $0.552 \pm 0.271$ & $0.270 \pm 0.258$ & 2.955 & .005 \\
Systolic inflow area, $\mathrm{mm}{ }^{2}$ & $23.18 \pm 11.37$ & $10.00 \pm 7.88$ & 4.087 & $<.001$ \\
Parent vessel flow rate, $\mathrm{mL} / \mathrm{s}$ & $2.84 \pm 0.73$ & $3.50 \pm 0.64$ & -2.746 & .009 \\
\hline
\end{tabular}

Note:-SD indicates standard deviation.

Table 4: Preprocedural hemodynamic qualitative inflow zone at the aneurysm neck

\begin{tabular}{lcccccc}
\hline & \multicolumn{2}{c}{ 6-Month Follow-Up } & & \multicolumn{2}{c}{ 12-Month Follow-Up } \\
\cline { 2 - 3 } \multicolumn{1}{c}{ Response } & $\begin{array}{c}\text { Remnant } \\
(\boldsymbol{n}=19)\end{array}$ & $\begin{array}{c}\text { Occlusion } \\
(\boldsymbol{n}=21)\end{array}$ & & $\begin{array}{c}\text { Remnant } \\
(\boldsymbol{n}=10)\end{array}$ & $\begin{array}{c}\text { Occlusion } \\
(\boldsymbol{n}=30)\end{array}$ \\
\hline Proximal neck & 11 & 3 & & 6 & 8 \\
Lateral side + distal neck & $7+1$ & $12+6$ & & $4+0$ & $15+7$ \\
$\chi 2$ analysis $(P$ value $)$ & Significant difference $(.004)$ & & No significant difference $(.13)$ \\
\hline
\end{tabular}

ophthalmic/supraclinoid) segments of the ICA (Bouthillier nomenclature).

\section{Clinical Follow-Up}

One patient without an aneurysm occlusion at 6 months missed the 12 month follow-up and only a 6-month comparison could be included. Another patient with an occlusion at 12 months missed the 6-month follow-up and only a 12-month comparison could be included (On-line Figure). Also, 40 aneurysms were screened for the comparison at 6 and 12 months. Two neuroradiologists had moderate interrater reliability $(\kappa=$ $0.738, P<.001)$, with a third expert for the first two neuroradiologists' disagreements. After 6-month (173.7 \pm 48.1 days) and 12-month (367.8 \pm 83.4 days) follow-ups, $21 \quad(21 / 40$ [52.5\%]) and 30 aneurysms (30/40 [75.0\%]) were occluded, respectively.

\section{Geometric Comparison}

There were significant differences in the aneurysm sac size, perpendicular height, maximum height, ostium maximum diameter, ostium area, and size ratio for different treatment response groups at 6 and 12 months. Among these, the ostium maximum diameter showed the most pronounced difference (Tables 2 and 3). There was no significant difference in aspect ratio at either time point.

\section{Hemodynamic Qualitative Comparison}

Two independent analysts trichotomously determined hemodynamic inflow zone at the aneurysm neck level with good consensus $(\kappa=0.754$, $P<.001)$. Qualitative analyses at the

\section{RESULTS}

\section{Patient Demographics}

Thirty-eight patients (mean \pm SD age, $53.7 \pm 13.4$ years [range, 26-81 years]) with 41 target aneurysms underwent subsequent FD procedures and were included in the study. In 3 patients, 2 target aneurysms were close to each other, and $1 \mathrm{FD}$ was deployed for both to achieve the coverage of the 2 ostia at the same time. Three of the 38 patients (7.9\%) were men (mean $\pm \mathrm{SD}$ age, $48.3 \pm 7.6$ years [range, 40-55 years]), and 35 were women (mean \pm SD age, $54.2 \pm$ 13.7 years [range, 26-81 years]). There was no significant difference $(P>.05)$ in age between sexes. Apart from 1 middle cerebral artery aneurysm (M1 segment), the aneurysms were situated in the C4 to C6 (cavernous, clinoid, aneurysm neck revealed that subjects with an inflow zone on the proximal neck in the remnant group were statistically more frequent than subjects with other inflow zones at 6 months $(P=.004)$ (Table 4$)$ but not at 12 months $(P=.13)$ (Table 4$)$.

\section{Hemodynamic Quantitative Comparison}

For preprocedural hemodynamic quantitative parameters at the ostium, there were significant differences in maximum inflow velocity, maximum inflow rate, systolic inflow rate ratio, and the systolic inflow area between the different treatment response groups at 6 months (Table 2). Significant differences for preprocedural maximum inflow rate, systolic inflow rate ratio, systolic inflow area, and parent vessel flow rate were observed between the different groups at 12 months (Table 3). The most 


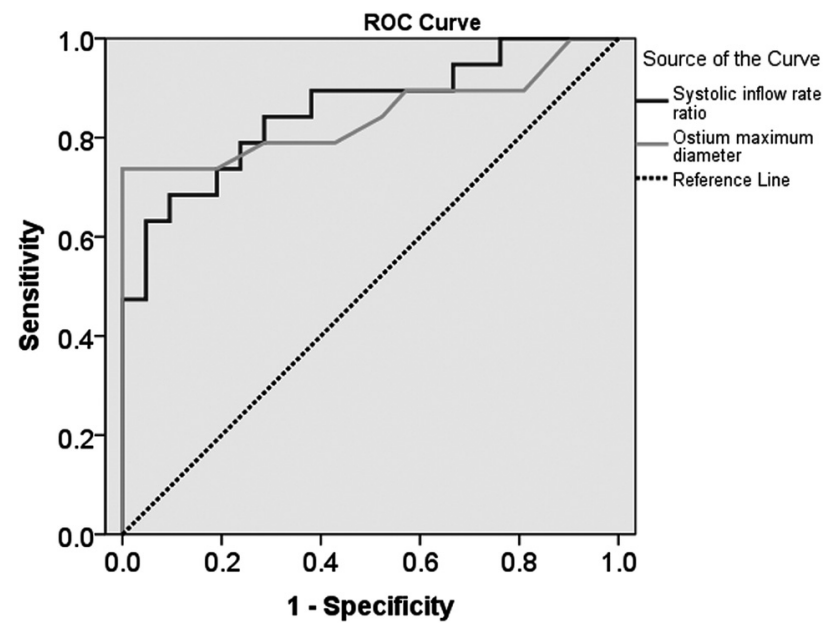

FIG 3. The receiver operating characteristic (ROC) curves of the systolic inflow rate ratio (dark line) and ostium maximum diameter (light line) against the occlusion at 6 months have areas under the curve (AUC) of 0.855 for the systolic inflow rate ratio and 0.843 for the ostium maximum diameter.

pronounced differences were observed for the systolic inflow rate ratio and systolic inflow area at 6 and at 12 months, respectively.

\section{Receiver Operating Characteristic Prediction Parameters}

As predicting parameters with receiver operating characteristic curves for the occlusion and remnant groups at 6 months, the areas under the curves of ostium maximum diameter and systolic inflow rate ratio reached 0.843 (95\% CI, 0.707-0.980; $P<.001$ ) and 0.855 (95\% CI, 0.735-0.974; $P<.001$ ), respectively (Fig 3). For the prediction of different responses at 12 months, areas under the curves of ostium maximum diameter and systolic inflow area were 0.883 (95\% CI, 0.759-1.000; $P<.001)$ and 0.860 (95\% CI, 0.730-0.990; $P=.001$ ), respectively (Fig 4). Based on the Youden index for favorable sensitivity and specificity, the optimum predictive cutoff at 6 months was $4.9 \mathrm{~mm}$ for the ostium maximum diameter (sensitivity, 73.7\%; specificity, 100\%; Youden index, 0.737 ) and 0.343 for the systolic inflow rate ratio (sensitivity, 68.4\%; specificity, 90.5\%; Youden index, 0.589). The optimal predictive cutoff at 12 months was $4.9 \mathrm{~mm}$ for ostium maximum diameter (sensitivity, 90.0\%; specificity, 83.3\%; Youden index, 0.733 ) and $13.35 \mathrm{~mm}^{2}$ for the systolic inflow area (sensitivity, 90.0\%; specificity, 80.0\%; Youden index, 0.700) (Fig 5).

\section{DISCUSSION}

This prospective study compared geometric and hemodynamic parameters in unruptured sidewall intracranial aneurysms for different FD treatment responses at 2 follow-up time points. Other studies have reported on the parameters for differentiation of the aneurysm response, ${ }^{15,16}$ but we highlighted the relationship between in vivo aneurysm hemodynamics and the treatment responses, and tried to give a hemodynamic explanation for the delayed occlusion. Our results showed geometric and hemodynamic differences between the occlusion and remnant groups at 6 and 12 months. In addition, 4D flow MR imaging before treatment with a FD gave important insights into the ostium hemodynamics that were helpful in predicting the treatment responses.

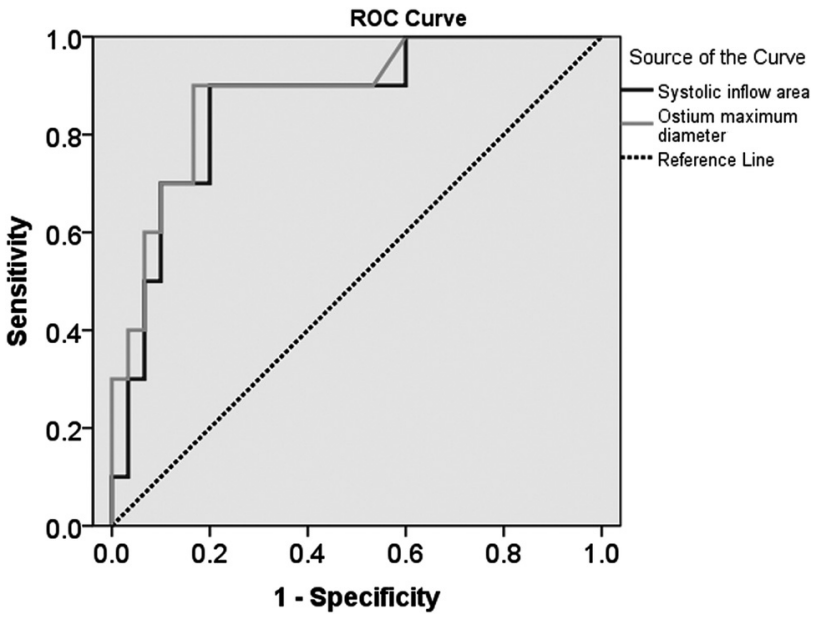

FIG 4. The receiver operating characteristic (ROC) curves of the systolic inflow area (dark line) and ostium maximum diameter (light line) against the occlusion at 12 months have areas under the curve (AUC) of 0.860 for the systolic inflow area and 0.883 for the ostium maximum diameter.

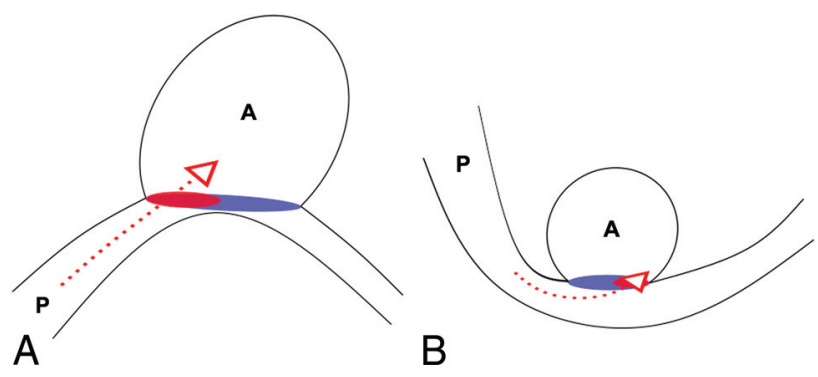

FIG 5. Illustrations of late and early occluded types of aneurysms reported in our results. A, A diagram of a late occluded aneurysm shows obvious sac size, height, ostium in geometries, and intense ostium hemodynamics with proximal neck inflow. $B$, Diagram of an early occluded aneurysm shows a smaller sac size, height, ostium in geometries, and mild ostium hemodynamics, with distal neck inflow. $\mathrm{P}$ and $\mathrm{A}$ represent parent vessels and aneurysms, respectively. Red dotted arrows symbolize inward blood flows. Oval red and purple regions at the ostium represent the inward and outward blood flow areas, respectively.

Among all the geometric parameters, a large ostium maximum diameter $(>4.9 \mathrm{~mm})$ was constantly and significantly associated with delayed occlusion, similar to a previous report. ${ }^{9}$

However, ostium hemodynamics provided new perspectives to investigate the influence of the FD. A proximal inflow area at the aneurysm neck represented a direct blood flow injecting into the aneurysm that might delay the occlusion. Because aneurysms in our study were mostly located in the tortuous ICA and the main flow often shifted to the lateral side of the artery by the inertial behavior after a sharp turn, the inflow zone on the lateral side was commonly observed. ${ }^{13}$

Furthermore, a strong inflow at the neck, especially a high systolic inflow rate ratio $(>0.343)$ and large systolic inflow area $\left(>13.35 \mathrm{~mm}^{2}\right)$, indicated more blood flow impinging on the aneurysm ostium, which would hinder the dampening of blood flow and even result in long-term patency. Our results showed that these 2 parameters were of importance and could well 
predict the FD treatment response. The advantage of this predictive tendency could be the possibility to plan a more individualized intervention to achieve a better patient outcome, such as a coiling aid or a combination of different patterns of FDs.

Although almost each geometric dimensional parameter shared the same trend between comparisons at 6 and 12 months, some variations could be observed in the hemodynamic parameters between the 2 time points. The preprocedural qualitative inflow zone and maximum inflow velocity were only significantly different between the different treatment response groups at 6 months and the parent flow rate between the different groups at 12 months. This suggests that some hemodynamic parameters may have different implications for short- and long-term responses, and provides a clue to further investigate the underlying reasons.

The FD may change local hemodynamics rather than simply covering the ostium and may need some time for a complete thrombosis inside the aneurysm and intimal endothelialization of the FD after the flow has been modified. According to the literature, ${ }^{27-30}$ the occlusion rate is variable. Our 6-month occlusion rate was slightly lower, but we found a similar rate at 12 months. Our results also showed that different hemodynamic initial conditions influenced the treatment response and thus provided more direct evidence to confirm the hemodynamic change effect on aneurysms. At present, due to metallic magnetic susceptibility and a low velocity from flow diversion, a direct in vivo hemodynamic MR imaging evaluation near the FD segment still has some limitations.

It is believed that the geometric and hemodynamic features are not the only influential factors. FD selection and deployment technique are also important to the treatment response. ${ }^{31}$ A fitted FD and its proper position in the target vessel are prerequisites, and thus we excluded 1 case with FD displacement at follow-up. Although 3 types of FDs were used, there was no obvious discrepancy in treatment responses (On-line Table). Antiplatelet therapy could also influence the thrombosis in the aneurysm. ${ }^{32}$ In our cohort, clopidogrel was stopped after the 6month follow-up unless there was a definite in-stent stenosis, but aspirin was continued. At least 8 aneurysms from our cohort occluded during the second 6-month period, and this may have been due to an additional effect exerted by clopidogrel discontinuity.

This study had some limitations. First, we only admitted patients with sidewall aneurysms because this type is considered a frequent and appropriate indication for flow diversion. ${ }^{7,33,34}$ In addition, its ostium can be better defined than those of other types. Second, although this in vivo study applied optimal acquisition by using PC MRI on a 3T system, MR imaging itself still has inherent limitations. For example, the presetting of the velocity sensitivity encoding parameter, the moderate spatial and temporal resolution according to our scan protocol may reduce MRI accuracy. ${ }^{35}$ Indeed, relatively low spatial resolution might imprecisely resolve a small region of interest for aneurysm ostium to some extent. Third, if the FD apparently changed the arterial angle because of its radial force, then the preprocedural hemodynamic analysis might not be fully consistent with the subsequent situation. A multicenter study with a large number of cases would seem to be essential for further analysis.

\section{CONCLUSIONS}

Intracranial aneurysms with a large ostium, systolic inflow rate ratio, and systolic inflow area may need a longer time for occlusion. Apart from conventional aneurysm geometric differences between occlusion and remnant groups, 4D flow MR imaging as a functional technique has the potential to well evaluate ostium hemodynamics and to hemodynamically explain FD treatment response in sidewall intracranial aneurysms.

Disclosures: Tianhao Su-RELATED: Grant: Swiss National Funds, Beijing Li Huanying Medical Foundation, Comments: SNF 32003B_160222 and SNF 320030_156813, Beijing Li Huanying Medical Foundation 2017.* Long JinRELATED: Grant: Beijing Li Huanying Medical Foundation, Comments: Beijing Li Huanying Medical Foundation 2017.* *Money paid to institution.

\section{REFERENCES}

1. Villablanca JP, Duckwiler GR, Jahan R, et al. Natural history of asymptomatic unruptured cerebral aneurysms evaluated at CT angiography: growth and rupture incidence and correlation with epidemiologic risk factors. Radiology 2013;269:258-65 CrossRef Medline

2. Chalouhi N, Daou B, Barros G, et al. Matched comparison of flow diversion and coiling in small, noncomplex intracranial aneurysms. Neurosurgery 2017;81:92-97 CrossRef Medline

3. Chalouhi N, Tjoumakaris S, Starke RM, et al. Comparison of flow diversion and coiling in large unruptured intracranial saccular aneurysms. Stroke 2013;44:2150-54 CrossRef Medline

4. Karmonik C, Anderson JR, Elias S, et al. Four-dimensional phase contrast magnetic resonance imaging protocol optimization using patient-specific 3-dimensional printed replicas for in vivo imaging before and after flow diverter placement. World Neurosurg 2017; 105:775-82 CrossRef Medline

5. Ouared R, Larrabide I, Brina O, et al. Computational fluid dynamics analysis of flow reduction induced by flow-diverting stents in intracranial aneurysms: a patient-unspecific hemodynamics change perspective. J Neurointerv Surg 2016;8:1288-93 CrossRef Medline

6. Pereira VM, Brina O, Delattre BM, et al. Assessment of intra-aneurysmal flow modification after flow diverter stent placement with four-dimensional flow MRI: a feasibility study. J Neurointerv Surg 2015;7:913-19 CrossRef Medline

7. Alderazi YJ, Shastri D, Kass-Hout T, et al. Flow diverters for intracranial aneurysms. Stroke Res Treat 2014;2014:415653 CrossRef Medline

8. Madaelil TP, Grossberg JA, Howard BM, et al. Aneurysm remnants after flow diversion: clinical and angiographic outcomes. AJNR Am J Neuroradiol 2019;40:694-98 CrossRef Medline

9. Briganti F, Napoli M, Leone G, et al. Treatment of intracranial aneurysms by flow diverter devices: long-term results from a single center. Eur J Radiol 2014;83:1683-90 CrossRef Medline

10. Larrabide I, Geers AJ, Morales HG, et al. Effect of aneurysm and ICA morphology on hemodynamics before and after flow diverter treatment. J Neurointerv Surg 2015;7:272-80 CrossRef Medline

11. Karunanithi K, Lee CJ, Chong W, et al. The influence of flow diverter's angle of curvature across the aneurysm neck on its haemodynamics. Proc Inst Mech Eng H 2015;229:560-69 CrossRef Medline

12. Futami K, Kitabayashi $\mathrm{T}$, Sano $\mathrm{H}$, et al. Inflow jet patterns of unruptured cerebral aneurysms based on the flow velocity in the parent artery: evaluation using 4D flow MRI. AJNR Am J Neuroradiol 2016;37:1318-23 CrossRef Medline

13. Futami K, Sano H, Kitabayashi $T$, et al. Parent artery curvature influences inflow zone location of unruptured sidewall internal 
carotid artery aneurysms. AJNR Am J Neuroradiol 2015;36:342-48 CrossRef Medline

14. Futami K, Sano H, Misaki K, et al. Identification of the inflow zone of unruptured cerebral aneurysms: comparison of 4D flow MRI and 3D TOF MRA data. AJNR Am J Neuroradiol 2014;35:1363-70 CrossRef Medline

15. Paliwal N, Tutino VM, Shallwani $\mathrm{H}$, et al. Ostium ratio and neck ratio could predict the outcome of sidewall intracranial aneurysms treated with flow diverters. AJNR Am J Neuroradiol 2019;40:288-94 CrossRef Medline

16. Paliwal N, Jaiswal P, Tutino VM, et al. Outcome prediction of intracranial aneurysm treatment by flow diverters using machine learning. Neurosurg Focus 2018;45:E7 CrossRef Medline

17. Higgins WE, Ojard EJ. Interactive morphological watershed analysis for 3D medical images. Comput Med Imaging Graph 1993;17: 387-95 CrossRef

18. Fernand M. Topographic distance and watershed lines. Signal Processing 1994;38:113-25

19. Wong SC, Nawawi O, Ramli N, et al. Benefits of 3D rotational DSA compared with 2D DSA in the evaluation of intracranial aneurysm. Acad Radiol 2012;19:701-07 CrossRef Medline

20. Dhar S, Tremmel M, Mocco J, et al. Morphology parameters for intracranial aneurysm rupture risk assessment. Neurosurgery 2008;63: 185-96; discussion 196-97 CrossRef Medline

21. Ahn SH, Prince EA, Dubel GJ. Basic neuroangiography: review of technique and perioperative patient care. Semin Intervent Radiol 2013;30:225-33 CrossRef Medline

22. Attali J, Benaissa A, Soize S, et al. Follow-up of intracranial aneurysms treated by flow diverter: comparison of three-dimensional time-of-flight MR angiography (3D-TOF-MRA) and contrastenhanced MR angiography (CE-MRA) sequences with digital subtraction angiography as the gold standard. J Neurointerv Surg 2016;8:81-86 CrossRef Medline

23. Cloft HJ, Kaufmann T, Kallmes DF. Observer agreement in the assessment of endovascular aneurysm therapy and aneurysm recurrence. AJNR Am J Neuroradiol 2007;28:497-500 Medline

24. Raghavan ML, Ma B, Harbaugh RE. Quantified aneurysm shape and rupture risk. J Neurosurg 2005;102:355-62 CrossRef Medline
25. Hanley JA, McNeil BJ. The meaning and use of the area under a receiver operating characteristic (ROC) curve. Radiology 1982;143: 29-36 CrossRef Medline

26. Bossuyt PM, Reitsma JB, Bruns DE, et al. STARD 2015: an updated list of essential items for reporting diagnostic accuracy studies. Radiology 2015;277:826-32 CrossRef Medline

27. Foa Torres G, Roca F, Noguera A, et al. Silk flow-diverter stent for the treatment of complex intracranial aneurysms: a one-year follow-up multicenter study. Interv Neuroradiol 2018;24:357-62 CrossRef Medline

28. Mohlenbruch MA, Herweh C, Jestaedt L, et al. The FRED flow-diverter stent for intracranial aneurysms: clinical study to assess safety and efficacy. AJNR Am J Neuroradiol 2015;36:1155-61 CrossRef Medline

29. Murthy SB, Shah S, Shastri A, et al. The SILK flow diverter in the treatment of intracranial aneurysms. J Clin Neurosci 2014;21:20306 CrossRef Medline

30. Becske T, Kallmes DF, Saatci I, et al. Pipeline for uncoilable or failed aneurysms: results from a multicenter clinical trial. Radiology 2013;267:858-68 CrossRef Medline

31. Ma D, Xiang J, Choi H, et al. Enhanced aneurysmal flow diversion using a dynamic push-pull technique: an experimental and modeling study. AJNR Am J Neuroradiol 2014;35:1779-85 CrossRef Medline

32. Texakalidis P, Bekelis $\mathrm{K}$, Atallah E, et al. Flow diversion with the Pipeline embolization device for patients with intracranial aneurysms and antiplatelet therapy: a systematic literature review. Clin Neurol Neurosurg 2017;161:78-87 CrossRef Medline

33. Petr O, Brinjikji W, Cloft $\mathrm{H}$, et al. Current trends and results of endovascular treatment of unruptured intracranial aneurysms at a single institution in the flow-diverter era. AJNR Am J Neuroradiol 2016;37:1106-13 CrossRef Medline

34. Brown RD Jr, Broderick JP. Unruptured intracranial aneurysms: epidemiology, natural history, management options, and familial screening. Lancet Neurol 2014;13:393-404 CrossRef Medline

35. Bouillot P, Delattre BMA, Brina O, et al. 3D phase contrast MRI: partial volume correction for robust blood flow quantification in small intracranial vessels. Magn Reson Med 2018;79:129-40 CrossRef Medline 